\section{Consensus Needed for Evaluating Safe and Adequate Anticoagulant Control}

W

e read with interest the recent article by Fitzmaurice et al. ${ }^{1}$ The primary outcome they reported was the point prevalence of patients achieving individual therapeutic international normalized ratio (INR) targets. Although the authors state that this method is routinely used in England, there is no clear consensus. In an attempt to standardize the evaluation of anticoagulant control, the INR was introduced, and diseasespecific INR target ranges were recommended.

In recent years, a variety of methods have been used to evaluate therapeutic control of the INR in England and elsewhere. Some of the most widely used methods include the following: (1) the proportion of INRs within target ranges ${ }^{2} ;(2)$ the proportion of time spent within the individual target ranges ${ }^{3}$; (3) the proportion of INRs within the target range $\pm 10 \%^{4}$; and (4) the mean $\pm 1 \mathrm{SD}$ INR for the clinic overall. ${ }^{5}$

There have been no recommendations for evaluating and reporting the use of the INR measurement of anticoagulant control either on the basis of routine clinical practice or in reports of clinical trials. This remains problematic because it prohibits the meta-analytic pooling of data and comparison of the effects of different interventions. Of particular importance is the need to apply each method of determining adequacy of control to clinically relevant outcomes such as bleeding or thromboembolic events and thus provide a means of comparing each of the methods for their sensitivity and specificity. Given the lack of consensus on evaluating INR control, it is encouraging that Fitzmaurice et $\mathrm{al}^{1}$ have provided both the point prevalence and proportion of time within target INR ranges. Consensus on a standard method of evaluation of what constitutes safe levels of anticoagulation and adequate clinical anticoagulant control is urgently required.

Fiona Taylor, MA

Shah Ebrahim, FFPHM

Bristol, England

1. Fitzmaurice DA, Hobbs FD, Murray ET, Holder RL, Allan TF, Rose P. Oral anticoagulation management in primary care with the use of computerized decision support and near patient testing: a randomized control trial. Arch Intern Med. 2000;160:2343-2348.

2. Calvin BT, Machin SJ, Barrowcliffe TW, et al, for the BCSH Haemostasis and Thrombosis Task Force of the British Society for Haematology. Audit of oral anticoagulent treatment. J Clin Pathol. 1993;46:1069-1070.

3. Rosendaal FR, Cannegieter SC, van der Meer FJ, Brit E. A method to determine the optimal intensity of oral anticoagulant therapy. Thromb Haemost. 1993;69:236-239.

4. Macgregor S, Hamley JG, Dunbar JA, Dodd TR, Cromarty JA. Evaluation of primary care anticoagulant clinic managed by a pharmacist. BMJ. 1996;312: 560
5. Fitzmaurice DA, Hobbs FD. Evaluation of a primary care anticoagulent clinic: reporting results should be standardised [letter]. BMJ. 1996;312:1609.

\section{Chronic Fatigue Syndrome, Decreased Exercise Capacihy, and Adrenal Insufficiency}

D e Becker et al, ${ }^{1}$ using a bicycle ergometer, found that the maximal workload and oxygen uptake attained by their patients with chronic fatigue syndrome (CFS) were almost half those achieved by the control subjects. The observation that the resting heart rate was higher in patients with CFS, as in other studies, led De Becker et $\mathrm{al}^{1}$ to suggest that "alteration in cardiac function is a primary factor associated with the reduction in exercise capacity in CFS." As someone whose reported ${ }^{2}$ recovery from CFS was characterized by a dramatic normalization of physical functionality, thanks to the glucocorticoid ${ }^{2}$ and mineralocorticoid ${ }^{3}$ properties of licorice, an old remedy for Addison disease, ${ }^{2} \mathrm{I}$ believe that adrenal insufficiency, rather than alteration in cardiac function, may primarily account for the reduction in exercise capacity in CFS.

The functions of glucocorticoid and mineralocorticoid hormones are so important that an insufficient production of those adrenal hormones has to result in impaired physical capacities. In fact, the observations made by De Becker et al ${ }^{1}$ in patients with CFS are virtually identical to those reported by Zelinskii et al, ${ }^{4}$ who, using a bicycle ergometer, just as De Becker and colleagues did, found that the working capacity, total volume of work done, and maximum oxygen consumption were lowered in patients with chronic corticoadrenal insufficiency.

Clinically, leaving aside my personal case,, 3 the view that the reduction in exercise capacity in CFS is primarily due to adrenal insufficiency lies in the astounding overlap of CFS with Addison disease. ${ }^{5}$ In fact, CFS shares 39 features with primary adrenal insufficiency ${ }^{6}$ including all the physical and neuropsychological symptoms listed in both the original and the revised criteria for $\mathrm{CFS},{ }^{6}$ as well as many other abnormalities. ${ }^{6}$ Specifically, to shed light on the findings of De Becker et $\mathrm{al}^{1}{ }^{1}$ it is important to point out that CFS and Addison disease share not only persistent fatigue and debilitation after exercise, ${ }^{6}$ but also reduction in cardiac dimensions and increased heart rate at rest, ${ }^{6}$ which obviously are secondary to the adrenal abnormalities found in either condition, such as hypocortisolism, impaired adrenal cortical function, reduced adrenal gland size, and antibodies against the adrenal gland. ${ }^{6}$

Notably, another symptom has lately been found in both CFS and Addison disease, this 40th shared feature being an increased sensitivity to chemical exposures. ${ }^{7}$ Most recently, it has been reported that patients with CFS have nocturnal awakenings more often than controls do. ${ }^{8}$ De- 
crease in sleep continuity, however, has also been observed in patients with Addison disease whose hydrocortisone replacement was withheld, ${ }^{9}$ which clearly suggests that the sleep fragmentation found in patients with $\mathrm{CFS}^{8}$ is a mere consequence of their cortisol insufficiency, ${ }^{6}$ just as in the case of hydrocortisone-deprived patients with Addison disease. ${ }^{9}$

The 40 features shared by CFS and Addison disease $^{6,7}$ (there are 41 if we include the reduction in exercise capacity ${ }^{1,4}$ ) and the fact that untreated subjects with Addison disease ${ }^{9}$ may develop the same abnormalities observed in patients with $\mathrm{CFS}^{8}$ should reasonably originate investigations aimed at determining whether the administration of both hydrocortisone and fludrocortisone acetate, the 2 classic steroids for Addison disease, could be of substantial benefit to patients with CFS as well, as I first suggested in $1996 .{ }^{10}$ However, rather surprisingly, despite the separate efficacy of hydrocortisone and fludrocortisone therapy for patients with CFS, ${ }^{6}$ the effects of the combined administration of these steroids on CFS symptoms have yet to be explored.

One might object that Rowe et $\mathrm{al}^{11}$ have lately found fludrocortisone to be ineffective for treating CFS. Unfortunately, Rowe and colleagues, by extemporaneously converting the commercial tablets of the drug to capsules, ${ }^{12}$ have undermined the reliability of their study, as have others. ${ }^{13}$

Riccardo Baschetti, MD Padua, Italy

1. De Becker P, Roeykens J, Reynders M, Mc Gregor N, De Meirleir K. Exercise capacity in chronic fatigue syndrome. Arch Intern Med. 2000;160:32703277.

2. Baschetti R. Chronic fatigue syndrome and liquorice. N Z Med J. 1995;108: 156-157.

3. Baschetti R. Liquorice and chronic fatigue syndrome. N Z Med J. 1995;108: 259.

4. Zelinskii BA, Vernigorodskaia MV, Vernigorodskii VS, Gamarnik LV, Palamarchuk AV. Assessment of the working capacity of patients with chronic cortico-adrenal insufficiency [in Russian]. Ter Arkh. 1987;59:132-134.

5. Baschetti R. Overlap of chronic fatigue syndrome with primary adrenocortical insufficiency. Horm Metab Res. 1999;31:439.

6. Baschetti R. Chronic fatigue syndrome: a form of Addison's disease. J Intern Med. 2000;247:737-739.

7. Nawab SS, Miller CS, Dale JK, et al. Self-reported sensitivity to chemical exposures in five clinical populations and healthy controls. Psychiatry Res. 2000 95:67-74

8. Knook L, Kavelaars A, Sinnema G, Kuis W, Heijnen CJ. High nocturnal mela- tonin in adolescents with chronic fatigue syndrome. J Clin Endocrinol Metab. 2000;85:3690-3692

9. García-Borreguero D, Wehr TA, Larrosa O, et al. Glucocorticoid replacement is permissive for rapid eye movement sleep and sleep consolidation in patients with adrenal insufficiency. J Clin Endocrinol Metab. 2000;85:42014206.

10. Baschetti R. Chronic fatigue syndrome and neurally mediated hypotension. JAMA. 1996;275:359.

11. Rowe PC, Calkins H, DeBusk K, et al. Fludrocortisone acetate to treat neurally mediated hypotension in chronic fatigue syndrome: a randomized controlled trial. JAMA. 2001;285:52-59.

12. Shah PT, Moore WE. Dissolution behavior of commercial tablets extemporaneously converted to capsules. J Pharm Sci. 1970;59:1034-1036.

13. Baschetti R. Treatment for chronic fatigue syndrome. Arch Intern Med. 1998; $158: 2266-2267$

\section{In reply}

Indeed, there seems to be a clinical overlap between CFS and Addison disease. However, a direct link between the endocrinological disturbances and the reduced exercise capacity has yet to be proved.

Unlike in Addison disease, in which hypocortisolemia is related to an autoimmune phenomenon, in CFS low cortisol levels could be attributable to altered intracellular mechanisms, eg, a decreased signal transduction to the receptors in the target organ. ${ }^{1}$ This could lead to decreased intracellular messenger RNA as a consequence of dysfunction of the 2-5A synthetase/ribonuclease L pathway in CFS exerting a negative control on protein synthesis. ${ }^{2,3}$ Both the novel low-molecular-weight ribonuclease $L^{2,3}$ and interaction of the ribonuclease L ankyrin domain with ABC transporters ${ }^{4}$ could play a role in this mechanism.

Pascale De Becker, PhD

Kenny De Meirleir, MD, PhD Brussels, Belgium

1. De Becker P, De Meirleir K, Joos E, et al. Dehydroepiandrosterone (DHEA) response to i.v. ACTH in patients with chronic fatigue syndrome. Horm Metab Res. 1999;31:18-21.

2. Suhadolnik RJ, Peterson DL, O'Brien K, et al. Biochemical evidence for a novel low molecular weight 2-5A-dependent RNase L in chronic fatigue syndrome. J Interferon Cytokine Res. 1997;17:377-385.

3. De Meirleir K, Bisbal C, Campine I, et al. A $37 \mathrm{kDa} 2-5 \mathrm{~A}$ binding protein as a potential biochemical marker for chronic fatigue syndrome. Am J Med. 2000; 108:99-105.

4. Herst CV, De Smet K, D'Haese A, et al. The interaction of RNase L ankyrin domain with $\mathrm{ABC}$ transporters might explain pain and many of the physiological disorders in CFS. In: Programs and abstracts of the AACFS Fifth International Research, Clinical and Patient Conference; January 25-29, 2001; Seattle, Wash. Abstract 069 